\section{TRANSEXUALIDADE E EDUCAÇÃO FÍSICA: UMA REVISÃO SISTEMÁTICA EM PERIÓDICOS DAS CIÊNCIAS DA SAÚDE}

\author{
TRANSSEXUALITY AND PHYSICAL EDUCATION: A SYSTEMATIC REVIEW IN \\ HEALTH SCIENCE JOURNALS
}

Jéssica Leite Serrano*, Iraquitan de Oliveira Caminha*, Isabelle Sena Gomes*

\begin{abstract}
Palavras chave: Transexualismo. Revisão. Ciências da Saúde. Educação Física.

Resumo: Este é um estudo de revisão sistemática sobre o tema transexualidade em periódicos do campo da saúde. O percurso metodológico seguiu as etapas de: (1) busca em bases eletrônicas (2005-2015), com os descritores "Educação Física", "exercício físico", "atividade física", "corpo", "práticas corporais", "transexual", "transexuais", e os operadores "and" e/ou "or"; (2) leitura dos títulos/resumos; (3) primeira inclusão; (4) aplicação do teste de relevância; (5) inclusão definitiva ( $n=29)$; (6) organização e discussão em categorias (construção sócio-histórica, políticas de saúde, militância e identidade de gênero), elaboradas a partir dos resultados. Verificou-se a predominância de estudos sobre aspectos biológicos e psicológicos, que tratam a transexualidade como patologia. Por outro lado, verificou-se também o crescimento de produções que analisam essa temática de forma mais holística nas Ciências da Saúde e consequentemente na Educação Física.
\end{abstract}

\section{Keywords:}

Transsexualism.

Review.

Health Sciences.

Physical Education.

\begin{abstract}
This is a systematic review study on transsexuality in health journals. The methodological trajectory was as follows: (1) search in electronic databases (2005-2015) with the descriptors "Physical Education", "physical exercises", "physical activities", "body", "bodily practices", "transsexual", "transsexuals", and the operators "and" and/or "or"; (2) reading of titles/abstracts; (3) first inclusion; (4) application of the relevance test; (5) final inclusion ( $n=29)$; (6) organization and discussion in categories (socio-historical construction, health policy, activism, and gender identity), based on the results. Studies about biological and psychological aspects that treat transsexuality as a pathology were found to prevail. On the other hand, an increase was also found in productions looking into this topic in a more holistic light in health sciences and consequently Physical Education.
\end{abstract}

Resumen: Este es un estudio de revisión sistemática sobre el tema de transexualidad en periódicos del área de la salud. El recorrido metodológico siguió las etapas de: (1) búsqueda en bases electrónicas (2005-2015), con los descriptores "Educación Física", "ejercicio físico", "actividad física" , "cuerpo", "practicas corporales", "transexual", "transexuales", y los operadores "and y/o"; (2) lectura de los títulos/resúmenes; (3) primera inclusión; (4) aplicación del teste de relevancia; (5) inclusión definitiva ( $n=29)$; (6) organización y discusión en categorías (construcción sociohistórica, políticas de salud, militancia e identidad de género), elaboradas a partir de los resultados. Se verificó el predominio de estudios sobre aspectos biológicos y psicológicos, que tratan la transexualidad como patología. Por otro lado, se verificó también el crecimiento de producciones que analizan esa temática de manera más holística en las ciencias de la salud y, consecuentemente, en la Educación Física.
*Universidade Federal da Paraíba. João Pessoa, PB, Brasil.

E-mail: jessica_jp4@ hotmail.com; caminhairaquitan@gmail.com; euisabelle@yahoo.com.br

Recebido em: 19-05-2016 Aprovado em: 27-07-2017 


\section{INTRODUÇÃOO}

O descortinar de saberes em torno da existência das pessoas trans começou a acontecer em meados do século XX (BENTO, 2014). Por volta de 1950, foram publicados os primeiros estudos que "[...] registraram e defenderam a especificidade do "fenômeno transexual"' (BENTO; PELÚCIO, 2012, p. 570). Desde então, a literatura para estudos na área ganhou terreno e consistência. A transexualidade é um fenômeno complexo que tem várias possibilidades de estudos e intervenções. Para Santos (2010), ela é um dispositivo biopolítico, produzido em determinado momento histórico com a finalidade de ajudar na sustentação de determinados regimes de verdade.

Em linhas gerais, o estudo da transexualidade se dá principalmente sob duas ópticas: a das Ciências da Saúde/Biológicas e a das Ciências Sociais. Para a primeira, os transexuais são vistos como pessoas acometidas pela disforia de gênero (DG), ou seja, não apresentam conformidade entre sexo biológico (de base cromossômica/genital) e gênero (ARÁN, 2006; CASTEL, 2001). Para a segunda, a transexualidade surge como uma questão identitária. $\mathrm{Na}$ concepção de Bento (2014), a visão sociológica se confronta com a das Ciências da Saúde/ Biológicas, que caracteriza a transexualidade como uma doença mental, relacionando-a ao campo da sexualidade e não do gênero. A opinião da autora evidencia que uma década atrás a separação entre as áreas ainda era mais que virtual, envolvia certa raiz epistemológica nos saberes produzidos, o que consequentemente distanciava os diálogos e refletia na crença legitimada em um discurso de caráter desviante como sinônimo de patológico.

Longe de estabelecer generalizações ou oposições, nos últimos anos, a expectativa pela publicação do Manual de Diagnóstico e Estatística dos Transtornos Mentais 1 também acalorou debates acerca do tema, implicando o aumento da sua visibilidade e a produção de cada vez mais estudos científicos, de modo que atualmente desenha-se um cenário de maior abertura para o diálogo multidisciplinar (CARVALHO, 2014). Apesar da diferença nas abordagens, há um consenso: a pessoa transexual está insatisfeita com algumas das suas condicionantes biológicas e busca alternativas para manter em equilíbrio o que deseja ser e 0 que é. Essa busca se estabelece em virtude da gramática normativa de gênero, que é fundada em uma matriz binária heterossexual.

Ressalta-se neste ponto a força compulsória da heteronormatividade, que opera inclusive no interior das práticas esportivas (GRESPAN; GOELLNER, 2014) para determinar posições sociais para aqueles(as) que vivenciam outras sexualidades e expressões de gênero (PETRY; MEYER, 2011).

O interesse deste estudo pelas produções acadêmicas nas Ciências da Saúde, sobretudo envolvendo a Educação Física enquanto área do conhecimento que organiza, planeja e executa intervenções junto à população, deu-se a partir da observação de casos como o de Tereza Brant (TECIDIO, 2015), homem trans que revelou em vários portais on-line seu gosto pelos exercícios físicos para a manutenção do peso e da massa muscular ${ }^{2}$. Seu relato sugere que o exercício físico não se limita ao controle dos processos biológicos, mas também pode influenciar na construção da identidade. Além disso, pode servir como instrumento para o alcance de preferências e características

1 Nesta edição do DSM-5, apesar do apelo dos movimentos sociais pela retirada da classificação da transexualidade como transtorno, apenas os termos foram mudados, passando de Transtorno de Identidade de Gênero para Disforia de Gênero.

2 Ver a matéria de Tecidio (2015). 
físicas idealizadas, que podem ter relação com a criação e/ou reprodução de estereótipos construídos culturalmente.

O caso de Nathalie Gassel, uma jovem fisiculturista que nega seu corpo e "malha" para forjar uma nova identidade sexual (uma "mulher viril"), com quem Malysse (2008) dialoga em seu diário de campo, também colaborou para a criação deste estudo, que surge em um momento em que a temática adquire repercussão política nacional e internacional em todas as instâncias sociais, tocando diretamente a Educação Física por meio das Olimpíadas e das novas políticas de inclusão de transexuais nas competições.

Atento à atualização dos debates sobre o tema e às novas demandas sociais, no dia 24 de janeiro de 2016, o Comitê Olímpico Internacional (COI) (INTERNATIONAL..., 2015) divulgou um documento com diretrizes para a participação de pessoas transexuais sem transgenitalização em competições esportivas (transgender guidelines) a partir dos Jogos Olímpicos do Rio de Janeiro ${ }^{3}$. O objetivo seria "abrir as portas" para pessoas trans em competições, considerando índices aceitáveis para a participação (como nível de testosterona), sem que necessariamente tenham que passar pelo processo de transgenitalização.

Considerando os casos citados, este estudo buscou, em um primeiro momento, periódicos na área da saúde que ajudassem a esclarecer se o exercício físico tem sido utilizado por pessoas trans como instrumento de intervenção sobre o corpo e solidificação de identidades. Em outros termos, descrições ou relatos de processos de masculinização ou feminização dos corpos trans viabilizados não só pela Medicina, mas também pelo exercício físico. Com esse objetivo, foi realizada uma busca na Biblioteca Virtual em Saúde (BVS), com os descritores "Educação Física", "exercício físico", "atividade física", "corpo", "práticas corporais", "transexual" e "transexuais"; e os operadores "and" e/ou "or". Contudo, apesar das combinações, os artigos encontrados não responderam ao objetivo da pesquisa. Desta forma, verificou-se a carência de pesquisas relacionando transexuais e exercício físico, tornando esse apanhado da literatura necessário tanto para colocar em perspectiva os saberes já formulados como para a construção de novos saberes, sobretudo no interior de áreas em que a temática é pouco discutida, como a Educação Física.

Para Nunes e Saraiva (2010), a Educação Física ainda não consolidou seus estudos dentro das temáticas de gênero, apesar da sua necessidade de dialogar com todos os segmentos sociais e da importância que esses estudos vêm assumindo no meio acadêmico. Reforçando esse argumento, enquanto pesquisadores da área de gênero já tocaram na questão da participação de transexuais em Olimpíadas, estudos na área da Educação Física ainda são escassos (CAVANAGH; SYKES, 2009; LESSA; VOTRE, 2013).

Devido à escassez de publicações nacionais sobre o tema, este estudo busca colaborar com as discussões sobre transexualidade e sua relação com a Educação Física, identificando e analisando artigos acadêmicos - à luz de autores como Berenice Bento, Michel Foucault e Márcia Arán - publicados nos últimos dez anos em periódicos das Ciências da Saúde ${ }^{4}$, especificamente disponíveis na BVS, e que envolvam o universo transexual. A opção pelo recorte se deu devido ao período conter a maior parte das publicações indexadas sobre 0 assunto.

3 Desde 2004, atletas com cirurgia pré-puberdade estavam incluídos.

4 Este artigo adota a divisão de áreas estabelecida pela Coordenação de Aperfeiçoamento de Pessoal de Nível Superior (Capes), a qual compreende que as "Ciências da Saúde" (4.00.00.00-1) incluem as seguintes subáreas: Medicina, Odontologia, Farmácia, Enfermagem, Nutrição, Saúde Coletiva, Fonoaudiologia, Fisioterapia e Terapia Ocupacional e Educação Física. 


\section{PERCURSO METODOLÓGICO}

Este estudo é caracterizado como revisão sistemática (de natureza qualitativa), compreendida por Sampaio e Mancini (2007) como uma pesquisa que utiliza a literatura sobre determinada temática, e, ainda, estratégias de intervenção específicas para realizar buscas de análise crítica e síntese dos dados obtidos. A versatilidade da revisão sistemática possibilita que sejam realizadas pesquisas pelas ópticas qualitativa e quantitativa e "[...] os resultados podem ser expostos na forma de conclusão, análise ou síntese" (GOMES; CAMINHA, 2014, p. 398).

Para a realização da pesquisa foram seguidas as seguintes etapas: definição dos descritores e bases de dados; garimpagem das publicações; leitura dos títulos e resumos; primeira reunião de consenso; exclusão dos artigos cujo resumo distanciava-se da temática; aplicação do teste de relevância e qualidade das pesquisas; leitura do texto completo; segunda reunião de consenso; inclusão/exclusão definitiva; extração, síntese e interpretação dos textos; redação do texto final (GOMES; CAMINHA, 2014).

A base de dados selecionada foi a BVS, com as seguintes bases: LiLACS, IBECS, MEDLINE, Biblioteca Cochrane e Scielo. A pesquisa disponibilizou um total de 7.372 estudos, sendo 529 associados ao descritor "transexual", 517 ao descritor "transexuais", 3.159 ao descritor "transexualidade" e 3.167 ao descritor "transexualismo". Os critérios do teste de relevância para inclusão dos textos foram: disponibilidade de texto completo em português; publicação entre 2005 e 2015 em periódico de classificação B2 ou superior (interdisciplinar) no webqualis; artigo original (excluem-se teses, dissertações e estudos secundários). Foram incluídos, na primeira análise, apenas os estudos que contemplaram todas essas exigências.

A etapa seguinte envolveu a leitura dos resumos $(n=39)$, textos completos e a reunião de consenso para inclusão/exclusão definitiva. Foram excluídos artigos que fugiam da temática e/ou não contemplavam a proposta do estudo. A busca resultou em um corpus composto por 29 artigos $(n=29)$, que foi dividido em quatro categorias sinalizadas pelos próprios estudos, as quais foram analisadas de forma conjunta e tendo como pano de fundo os estudos de gênero, sobretudo as discussões com autores como Michel Foucault, Berenice Bento e Márcia Arán.

\section{RESULTADOS E DISCUSSÃO}

Os artigos incluídos neste estudo foram publicados em 18 periódicos distintos. 0 período de tempo para publicação proposto na presente pesquisa foi de dez anos, entre 2005 e 2015, todavia, nenhum estudo foi publicado no ano de limite inferior de tempo e apenas seis foram publicados antes de 2010. Nota-se, assim, que se trata de estudos recentes. No que se refere às temáticas, foi registrada uma distribuição dos trabalhos entre três abordagens principais: aspectos relacionados à saúde, movimento LGBT (Lésbicas, Gays, Bissexuais, Travestis, Transexuais e Transgêneros) e aspectos individuais.

A partir da leitura sistemática do conteúdo dos artigos, quatro categorias foram elaboradas para análise: (1) construção sócio-histórica da transexualidade - abordando os descritores temáticos: marcadores sociais da diferença, heteronormatividade e corpo, profissionais do sexo, bioética e história; (2) políticas de saúde - abordando os temas de patologização, despatologização, medicalização, políticas públicas, transgenitalização, diagnóstico e sintoma; (3) militância - abordando desconstrução/discurso normativo e direitos 
humanos; e (4) questões de identidade de gênero - abordando não pertencimento, apoio social, família, performance e saúde mental.

\subsection{Categoria (1) Construção sócio-histórica da transexualidade}

As primeiras cirurgias de transgenitalização ocorreram a partir do ano de $1920 \mathrm{em}$ pessoas hermafroditas (que nasceram com genitálias masculinas e femininas). Apenas em 1966, a partir dos estudos de Harry Benjamim (1885-1986), que o conceito de transexualismo foi criado com o intuito de descrever o fenômeno transexual (ARÁN, 2006). Para Benjamin, a pessoa transexual não tem uma concordância entre os sexos e os seus componentes psicossociais e biomorfológicos, acreditando que o melhor tratamento para o transexualismo é o hormonal e o cirúrgico (PERELSON, 2011).

Muitos estudos associam o surgimento das categorias de gênero, entre elas a de transexual, ao sistema heteronormativo, que há anos se formalizou por meio do discurso médico e estabeleceu as regras do que é considerado normal ou patológico, do que é masculino e do que é feminino, do que é saúde e do que é doença (ARÁN, 2006; LIONÇO, 2009). Pela cientificidade dos saberes médicos, eles adquiriram maior credibilidade para explicar os motivos que levam uma pessoa a ser transexual (ALMEIDA; MURTA, 2013).

Em virtude disso, a transexualidade se constituiu e se encontra até hoje atrelada aos aspectos médicos, biológicos e patologizantes, começando pelo próprio termo "transexualismo", recorrente em muitos artigos, no qual o sufixo "ismo" denota relação com doença. O transexualismo é um transtorno em que não existe coerência entre o sexo e o gênero e a solução é a cirurgia de mudança de sexo associada ao uso de hormônios (TEIXEIRA, 2006; SAMPAIO; COELHO, 2012). Essa definição é frequente nos artigos encontrados, o que demonstra estar a transexualidade ainda associada a doença.

Observou-se que transexual e travesti ainda são categorias confusas entre pessoas leigas e até mesmo especialistas (PERES; TOLEDO, 2011). Isso se dá porque ambos se identificam como sujeitos pertencentes a um gênero que não corresponde com o sexo do nascimento; a diferença é que as pessoas travestis apresentam uma ambiguidade sexual na afirmação da sua identidade (LIONÇO, 2009).

Segundo os estudos, a pessoa transexual ainda sofre com o estigma da associação à profissional do sexo e com agressões transfóbicas, tendo dificuldades também em estabelecer uma carreira de trabalho (SAMPAIO; COELHO, 2012). A transfobia pode ser compreendida como formas de exclusão e violência contra pessoas que se expressam sexualmente pela adoção de um gênero de forma divergente da heteronormativa estabelecida e consolidada socialmente (ALMEIDA; MURTA, 2013).

Nos últimos anos, teóricos de outras áreas - como as Ciências Sociais - vêm buscando compreender esse fenômeno por uma óptica nova (ALMEIDA; MURTA, 2013). 0 crescimento e a visibilidade dessas novas formas de "expressão e existência" vêm quebrando o binarismo propagado pelas Ciências Médicas (PERES; TOLEDO, 2011), todavia, no cenário brasileiro, ainda predomina a visão patologizada (ALMEIDA; MURTA, 2013).

A transexualidade nasceu no berço patologizante da Medicina e hoje alguns dos seus representantes lutam contra essa raiz. Apesar disso, a chave da doença, na qual a 
transexualidade foi historicamente incluída, e que divide opiniões até mesmo no interior dos atuais grupos militantes, implica diagnóstico e intervenção médica. A questão suscitada é que essa "doença" também é perpassada por normatizações de caráter político que se inclinam para a manutenção de relações de saber/poder sustentadas pelo binômio doença-cura e pela definição no discurso do que é ou não desviante. Sua inclusão e posterior retirada do campo das prevenções e delírios mostram quão instáveis são as concepções do que é ou não considerado patologia. A própria ideia de desvio, como nos lembra Becker (2008) acerca dos comportamentos, em sua proposta de teoria interacionista, parece algo bastante relativo de acordo com o grupo em que o sujeito está inserido.

Assim, o homossexual, por exemplo, antes patologizado por seu comportamento desviante da matriz de inteligibilidade binária, poderá considerar desviante aquele que "comporta-se" de modo distinto e, por esse motivo, não incorporar o estigma de doente ou perverso. Nesta premissa não está implícito que a homossexualidade seja uma conduta/ comportamento, mas que, segundo Becker (2008), cada grupo considera desviante aqueles que não são seus pares ou não se adequam aos padrões normativos adotados.

Retornando à questão do saber médico, pensar a heteronormatividade como normal é pensar a transexualidade como desvio e, sendo assim, algo passível de normatização pela Medicina. Tais características nos levam a crer que a transexualidade é um dispositivo, e, enquanto dispositivo, implica um conjunto de saberes e discursos que a colocaram como fenômeno médico. Santos (2010) apoia-se em Foucault para a construção dessa hipótese, na medida em que, assim como este autor, entende dispositivo como uma construção articulada de discursos envolvendo saberes (dominantes), poderes (legitimados socialmente) e verdades (ditas e não ditas): "Em suma, o dito e o não dito são os elementos do dispositivo. 0 dispositivo é a rede que se pode tecer entre estes elementos" (FOUCAULT, 1984, p. 244). O conceito de raiz foucaultiana permite a análise de certos mecanismos de poder e dominação, a exemplo do controle panóptico exercido sobre a sexualidade na modernidade, mas não se restringe a esse fim, como lembra Deleuze (1990), que o trata como um conceito operatório de linhas emaranhadas convergentes, as quais incidem sobre a subjetividade e os sujeitos.

Sobre essa questão, Foucault (1984) nos lembra que a própria teoria é uma prática e, portanto, uma forma de exercer poder; uma prática que atua tomando para si a capacidade discursiva do outro. Desse modo, implantar um discurso de verdade sobre a transexualidade é negligenciar outros discursos:

Ora, o que os intelectuais descobriram recentemente é que as massas não necessitam deles para saber; elas sabem perfeitamente, claramente, muito melhor do que eles; e elas o dizem muito bem. Mas existe um sistema de poder que barra, proíbe, invalida esse discurso e esse saber (FOUCAULT, 1984, p. 71).

Seguindo a pista de Santos (2010), este estudo entende que as publicações em periódicos das Ciências da Saúde sobre a transexualidade - embora tenha sido verificado que são escassas as pontes diretas com a Educação Física - têm papel relevante na produção de saberes e verdades adotados pela área. Isso porque a Educação Física, enquanto área de intervenção, busca, também, em outras áreas no interior das Ciências da Saúde, ferramentas para o planejamento das intervenções junto à população (seja no esporte, na escola, nas academias, nos clubes, etc.). 


\subsection{Categoria (2) Políticas de Saúde}

Dos 29 artigos analisados, 12 têm relações diretas com esta categoria. Políticas de saúde para as pessoas transexuais é um assunto recorrente, direta ou indiretamente, na maior parte dos artigos. De acordo com as publicações encontradas, as pessoas transexuais são pessoas afetadas por um transtorno cujas identidades de gênero não são compatíveis com o corpo que elas possuem (PETRY; MEYER, 2011; SAMPAIO; COELHO, 2012). A ideia de transtorno retoma a hipótese de patologização da transexualidade e consequentemente corrobora a sua análise sob a perspectiva da doença em periódicos das Ciências da Saúde.

Do grego pathos, que significa sofrimento ou doença, e logos, que significa estudo, patologia é o estudo das doenças. Patologização é um conceito desenvolvido nos estudos de gênero por Judith Butler (2009) e, enquanto ação, implica transformar algo em doença ou anomalia, mesmo que não seja. Considerando o que escreve Canguilhem (2009), patologizar poderia ser alocar forçosamente alguma categoria ou segmento em uma condição de oposição ao normal. Grosso modo, é dessa ideia simples que parte a interpretação de Butler sobre 0 discurso em volta do dispositivo da transexualidade. A autora sugere ainda a necessidade de despatologização desta, sem deixar de frisar o quão complexo pode ser esse processo.

Carregar o estigma de doente significa ter que se submeter a cuidados médicos. A Associação Internacional Harry Benjamin de Disforia de Gênero (HBGIDA) foi a responsável pela normatização do "tratamento" para as pessoas transexuais em todo o mundo, por meio do livro El fenómeno transexual, que estabelece os parâmetros para avaliar se as pessoas que demandam "tratamento" são transexuais de fato (BENTO, 2014). A Associação Psiquiátrica Americana (APA), em 1980, incluiu, na terceira versão do DSM, a transexualidade como um Transtorno de Identidade de Gênero (BENTO, 2014). Assim, a transexualidade passou a prever sintomas, tratamento, normas, diagnóstico, vigilância e consequentemente necessidade de intervenção médica, o que parece ter culminado com um processo de medicalização. Hoje ela é tratada pelo DSM-5 como Disforia de Gênero (ARAÚJO; LOTUFO NETO, 2014).

Em 1997, foi autorizada pelo Conselho Federal de Medicina (CFM) a realização de cirurgias de transgenitalização e modificação de caracteres secundários - sob o título de experimental - dentro dos hospitais universitários. Após cinco anos, uma nova resolução autorizou a realização dessas cirurgias dentro de hospitais públicos e privados, retirando o caráter experimental, desde que fosse seguida uma rígida seleção por uma equipe multidisciplinar para detectar o "transexualismo" durante um período de pelo menos dois anos (FRANCO et al., 2010; ARÁN, 2006; ARÁN; ZAIDHAFT; MURTA, 2008).

Sobre essa questão, Butler (2009, p. 95) argumenta que:

[...] se por um lado o diagnóstico de transtorno de identidade de gênero continua a ser valorizado por facilitar um percurso economicamente viável para a transformação corporal, por outro, a oposição ao diagnóstico se faz necessária, dado que ele insiste em considerar como doença mental o que deveria ser entendido como uma possibilidade, entre outras, de autodeterminação do gênero.

Esse é justamente o ponto de tensão experimentado pelos transexuais, de acordo com os estudos analisados. De um lado, a necessidade de incorporar o discurso da doença para acessar as políticas públicas de saúde; do outro, assumir um estigma de pessoa doente mesmo não se reconhecendo como tal. 
No ano de 2004, deu-se início às políticas voltadas para a população LGBT como um todo. Nesse período foi criado o Comitê Técnico Saúde da População LGTB no âmbito do Ministério da Saúde, por intermédio da Portaria no 2.227/GM (BRASIL, 2004). Esse debate se deu em virtude das necessidades singulares das pessoas transexuais na busca pela coerência entre o sexo e o gênero a que elas pertencem. Tendo isso em vista, os governos, em suas diversas esferas, começaram a atentar para as particularidades dessa população. Por essa razão, ao longo dos anos, foram sendo criados mecanismos que vêm auxiliando as pessoas transexuais na busca por um corpo com o qual se identifiquem.

Tratar a pessoa trans como pessoa doente é mais uma forma de lidar com aquilo que foge ao binarismo homem-mulher, colocando-a sob a chave do desvio, e, sendo desviante, é algo passível de controle e intervenção médica, o que faz com que os pacientes na condição de trans sejam submetidos à normatização das Ciências da Saúde para que consigam ajuda do Estado. Tal perspectiva é contrária à tendência de estudos, em especial nas Ciências Sociais, que buscam despatologizar a transexualidade, encarando-a como uma questão de identidade (ALMEIDA; MURTA, 2013).

Entre os artigos que compõem essa categoria, ainda há estudos como os de Melo et al. (2011), Lionço (2009), Arán e Murta (2009) e Teixeira (2006), os quais discorrem sobre as legislações que, ao longo dos anos, vêm regulando o acesso dessa população aos serviços públicos de saúde. Atualmente os serviços específicos oferecidos às pessoas transexuais são o tratamento hormonal e o cirúrgico, visando concretizar o processo de mudança na busca pelo gênero a que se sente pertencente, denominado de processo transexualizador. Dentro do Sistema Único de Saúde (SUS), estão disponíveis as etapas desse processo, e o Ministério da Saúde dispõe de diretrizes específicas para o SUS. Esse processo consiste em estratégias que visam à transformação dos caracteres sexuais (LIONÇO, 2009) e geralmente está associado às seguintes etapas: confirmação do diagnóstico por meio do laudo do psiquiatra; psicoterapia individual e em grupo; tratamento hormonal e tratamento cirúrgico (ARÁN; MURTA; LIONÇO, 2009). Desta maneira, há a necessidade de que o indivíduo reconheça-se como portador de um transtorno para que tenha acesso aos mecanismos de modificação do seu corpo, uma vez que esse acesso está condicionado à confirmação de um diagnóstico psiquiátrico (VENTURA; SCHRAMM, 2009; ARÁN; MURTA, 2009).

\subsection{Categoria (3) Militância}

Alguns estudos que contemplam a população transexual fazem relações com a militância do movimento LGBT. Esse movimento abrange pessoas lésbicas, gays, bissexuais, travestis e transexuais e vem se consolidando e obtendo visibilidade a nível mundial, buscando lutar por direitos e igualdade e combater a violência contra essa população (FACCHINI, 2009).

O movimento social LGBT transforma temas privados em pautas de questões de ordem pública e atua por meio de diversas ações sociais. Entre elas estão as paradas de orgulho LGBT, que buscam romper com a rotina e realizam performances de identidades e papéis sociais (JESUS, 2013). Além das paradas, o movimento LGBT realiza diversas ações que reivindicam, entre outras coisas: reconhecimento legal de relações afetivo-sexuais; livre expressão de gênero e orientação sexual; mudança de nome em documentos; acesso a políticas de saúde específicas; adoção de crianças; e proteção do Estado (CARRARA, 2010). 
No Brasil, as discussões sobre preconceito com pessoas LGBT e a elaboração de políticas públicas foram intensamente influenciadas por conferências e tratados internacionais, que tiveram uma participação essencial dos movimentos sociais e de representantes do governo (TAGLIAMENTO, 2015). A articulação desses movimentos nessas discussões teve repercussões positivas em relação às demandas propostas, como a criação da Portaria $n^{0}$ 2.836, de 1ํ de dezembro de 2011 (BRASIL, 2011), que discorre sobre a promoção da saúde integral LGBT; a ampliação da Portaria ํำ 2.803, de 19 de novembro de 2013 (BRASIL, 2013), que versa sobre o processo transexualizador no SUS; o Decreto $n^{0} 8.727$, de 28 de abril de 2016 (BRASIL, 2016), que dispõe sobre o uso do nome social. Todas essas conquistas foram alcançadas em virtude das demandas propostas e problematizadas pelos movimentos sociais, de maneira especial o movimento LGBT.

Assim, o movimento LGBT objetiva a desconstrução do discurso normativo na busca pela igualdade de direitos, problematizando e denunciando a violência e a violação de direitos sofridos por essas pessoas (LIONÇO, 2008). Com base nessa preposição, podemos compreender a militância LGBT como "um recurso" de defesa e de busca de benefícios para a população que ela abrange, incluindo as pessoas transexuais.

Cabe ressaltar que o Brasil não possui políticas públicas de atenção integral à saúde dos transexuais, um segmento dito vulnerável pelo seu histórico de segregação social (CARVALHO, 2011). Além disso, são recentes as conquistas de direitos e espaços em que o transexual é acolhido e compreendido em suas necessidades específicas, quer seja pelo pouco conhecimento dos profissionais e da população, quer seja por questões de matriz cultural e política. Isso é particularmente relevante se considerarmos que a 'transautonomia' não será alcançada sem a construção de uma rede jurídica, assistencial e social que lhe dê suporte e permita que a transexualidade possa ser vivida" (BUTLER, 2009, p. 95). Inclui-se entre os direitos recentemente conquistados, por exemplo, a nova interpretação da Lei de Registros Públicos, que prevê, desde meados de 2017, a possibilidade de mudança no registro civil de transexuais sem a necessidade de condicionamento à intervenção cirúrgica. Isso porque o Supremo Tribunal Federal (STF) passou a considerar o critério de constrangimento, provocado muitas vezes pela não convergência entre o nome social e o registro civil dos transexuais. Tal avanço, espera o STF, poderá dissolver uma série de outros constrangimentos e barreiras nas relações sociais, trabalhistas, etc.

\subsection{Categoria (4) Questões de Identidade de Gênero}

Os estudos que não estão atrelados às Ciências da Saúde analisam a transexualidade como uma questão de identidade de gênero, desassociando a imagem da pessoa transexual à doença/transtorno/patologia e encarando a transexualidade como uma identidade que destoa daquelas regidas por uma perspectiva da heteronormatividade, a qual restringe e limita as possibilidades de vivência das identidades. Assim, o entendimento de que os corpos transexuais "[...] embaralham as fronteiras entre o natural e 0 artificial, entre o real e o fictício e que denunciam, implícita ou explicitamente, que as normas de gênero não conseguem um consenso absoluto na vida social" (BENTO, 2014, p. 19) nos faz refletir sobre a ineficiência das normas de gênero em abranger todas as expressões.

Entre os artigos analisados, dois expressam de forma mais evidente a compreensão da transexualidade como uma questão de gênero desassociada de questões patologizantes 
e dialogam diretamente com a teoria queer. Peres e Toledo (2011) concebem as pessoas transexuais como novas formas de existência que ganharam visibilidade e emergência, e ultrapassam as definições de homem e mulher, heterossexuais e homossexuais, causando rachaduras na matriz binária. Bento (2014) nega a existência de uma identidade trans e considera a ocorrência de posições de identidade que se estabelecem a partir de sentimentos de negação e afirmação dos modelos socais que definem o ser homem e o ser mulher. Nesses estudos, portanto, a transexualidade se relaciona com as questões de identidade de gênero, que se constroem a partir dos modelos socialmente impostos.

\section{CONCLUSÕES E CONSIDERAÇÕES FINAIS}

O universo transexual tem sido tema de estudos de diversas áreas com grande repercussão nas últimas décadas. Vários campos têm se interessado pela temática da transexualidade, todavia, verificou-se que, em bases das Ciências da Saúde, ainda há predominância de estudos que tratam a transexualidade como patologia. Apesar disso, foi constatado um tímido e recente crescimento de produções que analisam essa temática de forma holística.

A proposição da transexualidade como dispositivo histórico e socialmente construído, tal qual nos inspira Foucault (1984) ao falar do dispositivo da sexualidade, não é algo novo. Isso implica dizer que ela se encontra envolvida no interior de um aparato discursivo respaldado por relações de poder/saber/verdade imperativas, construído a partir de elementos clínicos, científicos e de subjetividades; um dispositivo que opera muito mais vigilante e de forma positiva do que negativa e cujo diagnóstico ocupa um papel central. É a partir do diagnóstico que os transexuais são classificados, e é a partir dessa classificação que brotam, do interior do poder, outros discursos, como o da diferença contra o discurso da patologia. E no interior do próprio dispositivo estão as resistências.

Em relação aos objetivos da pesquisa, os estudos vinculados às bases selecionadas estão muitas vezes atrelados a aspectos biológicos e psicológicos, ou seja, têm sido discutidas formas de acesso e possibilidades de ofertas de serviços que atendam às necessidades da população trans. Também estão disponíveis, em menor número, estudos que abordam outras temáticas, embora nenhum faça interface direta com a Educação Física, revelando, assim, ser este um campo profícuo de estudo.

Concluiu-se, portanto, que ainda há carência de estudos que analisem a transexualidade sob uma óptica mais holística e social entre os periódicos específicos das Ciências da Saúde. Essa afirmação refletiu diretamente no objetivo inicial da presente pesquisa, o de identificar os estudos que relacionam Educação Física/exercício físico e os transexuais.

O exercício físico é uma ferramenta social que pode oferecer diversos benefícios aos seus praticantes, seja de ordem física ou psicossocial, e lida diretamente com o corpo, ajudando em sua modificação. As pessoas transexuais consideram o corpo a principal peça de reconhecimento social de sua identidade de gênero, e é por meio dele que elas obtêm a sua afirmação pessoal. Assim, falar em exercício físico corroborando a produção de corpos masculinizados ou feminizados não é algo tão distante. No entanto, a hipótese de que o exercício físico poderia servir como instrumento para a produção de tais corpos entre os transexuais - algo semelhante à construção protética já discutida alhures - não foi confirmada 
nos estudos encontrados; porém, isso não invalida a hipótese, apenas mostra uma lacuna de investigação sobre o tema, acentuada propositalmente por questões metodológicas.

As questões de ordem afetiva, emocional e cultural, como também os benefícios fisiológicos que podem ser associados às práticas corporais realizadas por pessoas transexuais, ainda demandam maiores estudos. Acreditando na importância do desenvolvimento das discussões entre os periódicos específicos das Ciências da Saúde, a investigação realizada limitou-se à realização de uma revisão sistemática na base de dados BVS com o intuito de ajudar no preenchimento futuro de possíveis lacunas de investigação no contexto da produção acadêmica em Educação Física. Dessa forma, sugere-se que pesquisas futuras dediquemse a uma interface mais direta com o universo da Educação Física, a fim de identificar as possíveis contribuições e nuanças do exercício físico, realizado pelas pessoas transexuais, para a construção sociocultural de identidades de gêneros.

\section{REFERÊNCIAS}

ALMEIDA, Guilherme; MURTA, Daniela. Reflexões sobre a possibilidade da despatologização da transexualidade e a necessidade da assistência integral à saúde de transexuais no Brasil.

Sexualidad, Salud y Sociedad, n. 14, p. 380-407, ago. 2013.

ARÁN, Márcia. A transexualidade e a gramática normativa do sistema sexo-gênero. Ágora, v. 9, n. 1, p. 49-63, jan./jun. 2006.

ARÁN, Márcia; MURTA, Daniela. Do diagnóstico de transtorno de identidade de gênero às redescrições da experiência da transexualidade: uma reflexão sobre gênero, tecnologia e saúde. Physis, v. 19, n. 1, p. 15-41, 2009.

ARÁN, Márcia; MURTA, Daniela; LIONÇO, Tatiana. Transexualidade e saúde pública no Brasil. Ciência e Saúde Coletiva, v. 14, n. 4, p. 1141-1149, jul./ago. 2009.

ARÁN, Márcia; ZAIDHAFT, Sérgio; MURTA, Daniela. Transexualidade: corpo, subjetividade e saúde coletiva. Psicologia e Sociedade, v. 20, n. 1, p. 70-79, jan./abr. 2008.

ARAUJO, Álvaro Cabral; LOTUFO NETO, Francisco. A nova classificação americana para os transtornos mentais: o DSM-5. Revista Brasileira de Terapia Comportamental e Cognitiva, v. 16, n. 1, p. 67-82, abr. 2014.

BECKER, Howard. Outsiders: estudos de sociologia do desvio. Rio de Janeiro: Zahar, 2008.

BENTO, Berenice. A reinvenção do corpo: sexualidade e gênero na experiência transexual. 2. ed. Rio de Janeiro: EDUFRN, 2014.

BENTO, Berenice; PELÚCIO, Larissa. Despatologização do gênero: a politização das identidades abjetas. Revista Estudos Feministas, v. 20, n. 2, p. 569-581, maio/ ago. 2012.

BRASIL. Portaria no 2.227/GM, de 14 de outubro de 2004. Dispõe sobre a criação do Comitê Técnico para a formulação de proposta da política nacional de saúde da população de gays, lésbicas, transgêneros e bissexuais - GLTB. Diário Oficial da República Federativa do Brasil, Brasília, DF, 14 out. 2004. Seção II, p. 24. 
BRASIL. Ministério da Saúde. Portaria n. 2.836, de $1^{\circ}$ de dezembro de 2011. Institui no âmbito do SUS a Política Nacional de Saúde Integral LGBT. Brasília, 2011. Disponível em: < http:// bvsms.saude.gov.br/bvs/saudelegis/gm/2011/prt2836 0112 2011.html>. Acesso em: 2 fev. 2017.

BRASIL. Ministério da Saúde. Portaria n. 2.803, de 19 de novembro de 2013. Redefine e amplia o processo transexualizador no SUS. Brasília, 2013. Disponível em: http://bvsms.saude. gov.br/bvs/saudelegis/gm/2013/prt2803 1911 2013.html. Acesso em: 2 fev. 2017.

BRASIL. Decreto ${ }^{\circ}$ 8.727, de 28 de abril de 2016. Dispõe sobre o uso do nome social e o reconhecimento da identidade de gênero de pessoas travestis e transexuais no âmbito da administração pública federal direta, autárquica e fundacional. Diário Oficial, Brasília, 28 abr. 2016. Disponível em: < http://www.planalto.gov.br/ccivil 03/ ato2015-2018/2016/decreto/D8727. htm>. Acesso em: 2 fev. 2017.

BUTLER, Judith. Desdiagnosticando o gênero. Tradução de André Rios. Physis, v. 19, n. 1, p. 95-126, 2009.

CANGUILHEM, G. O normal e o patológico. 6. ed. Rio de Janeiro: Forense Universitária, 2009.

CARRARA, Sérgio. Políticas e direitos sexuais no Brasil contemporâneo. Bagoas, v. 4, n. 5, p. 131-147, 2010.

CARVALHO, Diego de Sousa. 0 gênero e a "ciência da saúde": produção em torno da transexualidade no portal de pesquisa da biblioteca virtual em saúde. 2014. 101 f. Dissertação (Mestrado) - Faculdade de Saúde Pública, Universidade de São Paulo, São Paulo, 2014.

CARVALHO, Mário Felipe de Lima. A (im)possível pureza: medicalização e militância na experiência de travestis e transexuais. Sexualidad, Salud y Sociedad, n. 8, p. 36-62, ago. 2011.

CASTEL, Pierre-Henri. Algumas reflexões para estabelecer a cronologia do "fenômeno transexual" (1910-1995). Revista Brasileira de História, v. 21, n. 41, p. 77-111, 2001.

CAVANAGH, Sheila L.; SYKES, Heather. Cuerpos transexuales en las Olimpiadas: las politicas del Comité Internacional Olímpico em relación com I@s atletas transexuales en los juegos de Verano, Atenas 2004. Debate Feminista, v. 39, p. 40-74, abr. 2009.

DELEUZE, Gilles. ¿Qué es un dispositivo? In: BALIBAR, Etienne et al. Michel Foucault, filósofo. Traducción Wanderson Flor do Nascimento. Barcelona: Gedisa, 1990. p. 155-161.

FACCHINI, Regina. Entre compassos e descompassos: um olhar para o "campo" e para a "arena" do movimento LGBT brasileiro. Bagoas, v. 3, n. 4, p. 131-158, 2009.

FOUCAULT, Michel. Microfísica do poder. Rio de Janeiro: Graal, 1984.

FRANCO, Talita et al. Transgenitalização masculino/feminino: experiência do Hospital Universitário da UFRJ. Revista do Colégio Brasileiro de Cirurgiões, v. 37, n. 6, p. 426- 434, nov./dez. 2010.

GOMES, Isabelle Sena; CAMINHA, Iraquitan de Oliveira. Guia para estudos de revisão sistemática: uma opção metodológica para as Ciências do Movimento Humano. Movimento, v. 20, n. 1, p. 395-411, jan./mar. 2014. octógono. Movimento, v.20, n.4, p. 1265-1282, out./dez. 2014. 
INTERNATIONAL OLYMPIC COMMITTEE (IOC). Consensus Meeting on Sex Reassignment and Hyperandragenism. Lausanne, nov. 2015. Disponível em: <http://www.olympic.org/ Documents/Commissions PDFfiles/Medical commission/2015-11 ioc consensus meeting on sex reassignment and hyperandrogenism-en.pdf>. Acesso em: 2 fev. 2017.

JESUS, Jacqueline Gomes de. Alegria momentânea: paradas do orgulho de lésbicas, gays, bissexuais, travestis e transexuais. Gerais: Revista Interinstitucional de Psicologia, v. 6, n. 1, p. 54-70, jan./jun. 2013.

LESSA, Patrícia; VOTRE, Sebastião Josué. Carteira rosa: a tecnofabricação dos corpos sexuados nos testes de feminilidade na Olimpíada de 1968. Revista Brasileira de Ciências do Esporte, v. 35, n. 2, p. 263-279, abr./jun. 2013.

LIONÇO, Tatiana. Que direito à saúde para a população GLBT? Considerando direitos humanos, sexuais e reprodutivos em busca da integralidade e da eqüidade. Saúde e Sociedade, v. 17, n. 2, p. 11-21, abr./jun. 2008.

LIONÇO, Tatiana. Atenção integral à saúde e diversidade sexual no processo transexualizador do SUS: avanços, impasses, desafios. Physis, v. 19, n.1, p. 43-63, 2009.

MALYSSE, Stéphane Rémy Georges. Diário acadêmico. São Paulo: Estação das Letras e Cores, 2008.

MELLO, Luiz et al. Políticas de saúde para lésbicas, gays, bissexuais, travestis e transexuais no Brasil: em busca de universalidade, integralidade e equidade. Sexualidad, Salud y Sociedad, n. 9, p. 7-28, dez. 2011.

NUNES, Taise Maurice; SARAIVA, Maria do Carmo. A identidade de gênero (feminilidades e masculinidades) na mídia e nas práticas corporais: produção científica em revistas da Educação Física brasileira de 2000 a 2008. In: FAZENDO GÊNERO: DIÁSPORAS, DIVERSIDADES, DESLOCAMENTOS, 9., 2010, Florianópolis. Anais... Florianópolis: 2010. Disponível em: $<$ <ttp://www.fazendogenero.ufsc.br/9/resources/anais/1278290091_ARQUIVO_FAZENDOGENEROartigodocongresso-Maria[1]2[1].pdf>. Acesso em: 2 fev. 2017.

PERELSON, Simone. Transexualismo: Uma questão do nosso tempo e para o nosso tempo. Epos, v. 2, n. 2, p. 1-19, jul./dez. 2011.

PERES, William Siqueira; TOLEDO, Lívia Gonsalves. Dissidências Existenciais de Gênero: resistências e enfrentamentos ao biopoder. Revista Psicologia Política, v. 11, n. 22, p. 261277, dez. 2011.

PETRY, Analídia Rodolpho; MEYER, Dagmar Elisabeth Estermann. Transexualidade e heteronormatividade: algumas questões para a pesquisa. Textos e Contextos, v. 10, n. 1, p. 193-198, jan./jul. 2011.

SAMPAIO, Liliane Lopes Pedral; COELHO, Maria Thereza Ávila Dantas. Transexualidade: aspectos psicológicos e novas demandas ao setor saúde. Interface, v. 16, n. 42, p. 637-649, jul./set. 2012.

SAMPAIO, Rosana Ferreira; MANCINI, Marisa Cotta. Estudos de revisão sistemática: um guia para síntese criteriosa da evidência científica. Revista Brasileira de Fisioterapia, v. 11, n. 1, p. 83-89, jan./fev. 2007.

SANTOS, Paulo Reis dos. Tensões e desafios: LGBTS e o poder público? Revista de Psicologia da UNESP, v. 9, n. 2, p. 147-164, 2010. 
TAGLIAMENTO, Grazielle. Direitos humanos e a saúde: a efetivação de políticas públicas voltadas à saúde integral da população trans. In: BRASIL. Ministério da Saúde. Transexualidade e travestilidade na saúde. Brasília, 2015. p. 11-127.

TECIDIO, Luciana. Tereza Brant diz que ainda não fez sexo após a retirada dos seios. Ego,10 set. 2015. Disponível em: <http://ego.globo.com/famosos/noticia/2015/09/tereza-brant-diz-que-aindanao-fez-sexo-apos-retirada-dos-seios.html>. Acesso em: 20 dez. 2016.

TEIXEIRA, Marina Caldas. Mudar de sexo: uma prerrogativa transexualista. Psicologia em Revista, v. 12, n. 19, p. 66-79, jun. 2006.

VENTURA, Miriam; SCHRAMM, Fermin Roland. Limites e possibilidades do exercício da autonomia nas práticas terapêuticas de modificação corporal e alteração da identidade sexual. Physis, v. 19, n. 1, p. 65-93, 2009. 